\title{
Experimental Assessment of the Reciprocating Feed System
}

\author{
David E. Eddleman ${ }^{1}$, Dr. James B. Blackmon ${ }^{2}$ and Christopher D. Morton ${ }^{3}$ \\ University of Alabama in Huntsville Propulsion Research Center, Huntsville, AL, 35806
}

\begin{abstract}
I. Abstract
The primary goal of this project was to design, construct, and test a full scale, high pressure simulated propellant feed system test bed that could evaluate the ability of the Reciprocating Feed System (RFS) to provide essentially constant flow rates and pressures to a rocket engine. The two key issues addressed were the effects of the transition of the drain cycle from tank to tank and the benefits of other hardware such as accumulators to provide a constant pressure flow rate out of the RFS. The test bed provided $500 \mathrm{psi}$ flow at rates of the order of those required for engines in the 20,000 lbf thrust class (e.g., 20 to $40 \mathrm{lbs} / \mathrm{sec}$ ). A control system was developed in conjunction with the test article and automated system operation was achieved. Pre-test planning and acceptance activities such as a documented procedure and hazard analysis were conducted and the operation of the test article was approved by, and conducted in coordination with, appropriate NASA Marshall Space Flight Center personnel under a Space Act Agreement. Tests demonstrated successful control of flow rates and pressures.
\end{abstract}

\section{Technical Discussion}

The basic concept for an RFS is covered in patent number 6,314,978B1 titled Reciprocating Feed System for Fluids ${ }^{1}$ and in prior AIAA Joint Propulsion Conference papers ${ }^{2,3}$. This patent was originally assigned to McDonnell Douglas (a wholly owned subsidiary of The Boeing Company), but was donated to the University of Alabama in Huntsville in 2005. Other UAH patents related to the RFS are pending. Other work related to this topic is addressed by Flowmetrics ${ }^{3-6}$, and in patent number 3,213,804, titled Fluid Pressurizing System ${ }^{7}$. The RFS contains propellant in both of the main, low pressure, storage tanks and in two or, preferably, three, small, high pressure tanks. The small tanks would be filled initially before engine firing and would also fill after engine shutdown for multiple restart missions; this provides a significant improvement in the conditions needed for successful propellant acquisition in a microgravity environment, in that the static pressure exerted on surface tension screen devices is far less than for the larger main tanks. The small tanks sequentially expel liquid into the engine, vent, refill with liquid from the main tank, and then are re-pressurized. Our test results show that this cycle provides an essentially uniform pressure and flow rate. The use of small, lightweight tanks allows the RFS to operate at engine pressure ranges well above those normally associated with pressure fed systems and in the range of the majority of pump fed engines. This higher engine pressure results in smaller engines, increased expansion ratios, and higher specific impulses, all of which contribute to an overall increase in system performance, especially in terms of delivered payload for constant mission parameters, such as delta- $\mathrm{V}$ and thrust.

\section{Introduction}

The primary goal of experimental work relating to this project was to design, construct, and test an apparatus that could evaluate the ability of the RFS to provide controlled flow rate and pressure. The two key issues addressed were the effects of the transition of the drain cycle from tank to tank and the assessment of ancillary hardware such as accumulators to provide a constant pressure and flow rate out of the RFS. A control system was developed in conjunction with the test article and automated system controllability was achieved. Finally, pre-test activities such as a documented procedure and hazard analysis were conducted and the operation of the test article was approved by, and conducted in cooperation with, NASA Marshall Space Flight Center personnel under a Space Act Agreement.

\footnotetext{
${ }^{1}$ Jr. Propulsion Components Engineer, Qualis Corporation, 6767 Old Madison Pike Suite 105, Madison, AL. Student Member.

${ }^{2}$ Research Professor, Mechanical and Aerospace Engineering, Technology Hall S-227 The University of Alabama in Huntsville, Huntsville, AL 35899, AIAA Associate Fellow

${ }^{3}$ Graduate Student, Mechanical and Aerospace Engineering, Technology Hall S-227 The University of Alabama in Huntsville, Huntsville, AL 35899
} 


\section{Objectives}

The main objective was to develop a test bed that could be used for proof of concept tests. One key issue to be investigated was the effect of the valves opening and closing on the common RFS outflow, which simulates the flow to the engine. Ball valves were used as fill and drain valves in the test apparatus as would likely be the case in a flight rated vehicle system. Before fully opening and just prior to closing the outflow, pressurized water flowing through the valve would basically be flowing through a small slit or orifice. This restriction and resulting high velocity could lead to cavitation each time the RFS alternates outflow from one tank to another, and this could cause a change in flow rate. In addition, variations in the timing of the valves that are opening and closing to switch from one tank outflow to another would cause pressure and flow rate variations. It was desired to see if this could be alleviated or minimized with relatively fast valve cycle times and/or by overlapping the valve cycles. This overlapping was estimated to be on the order of several hundred milliseconds and would be small in comparison to overall drain cycle times of the run tanks. Another issue was to assess the effects of, and potential need for, pressure and flow rate regulating devices such as small liquid accumulators or venturi flow-meters to reduce pressure and flow rate fluctuations as the RFS alternates outflow from tank to tank. If a sufficiently steady outflow could not be accomplished with the standard RFS concept, which typically relies on the overlap of the valves opening and closing, then these components could be used to decrease the fluctuations. Although these components were not available for our initial tests, an estimate of the sizes and specifications of this hardware could be made from the resulting data. This test bed would also be used for follow on testing that would be investigating these and other aspects of the RFS concept associated with different performance aspects.

The second objective in the design and construction of the system was to develop a control system that could handle the automated timing sequences of several valves as well as allow for manual input or operation. The control system for this test bed was an open loop control, and the first step towards eventually automating the system with closed loop control in future series of tests. This system would need to work in conjunction with a data acquisition system and sensors, such as flow rate or liquid level sensors, that could provide the necessary sampling rates for good flow and pressure control.

\section{Test Bed}

It was determined that for initial testing, simple water flows would be sufficient to show proof of concept. Water flows would also be the safest form of testing to do while examining key design issues of the RFS concept. The test bed simulated a propellant feed system to an approximately 500 psi thrust chamber, in that the outflow of the RFS was routed through an orifice to simulate the pressure drop across an injector plate into the engine, and then discharged.

The system was designed to simulate the flow rates and pressures of an engine having of the order of $20,000 \mathrm{lbs}$ of thrust and operating at approximately $500 \mathrm{psi}$. An understandable concern is that large, rapid and/or cyclical/resonant changes in flow rate or pressure could initiate combustion instability. Our results show that the flow rate and pressure fluctuations are small, and infrequent (i.e., of the order of once every several seconds), and are therefore unlikely to contribute to combustion instability.

The initial design of the RFS test apparatus was centered primarily on the run tanks. Three Composite Over-Wrapped Pressure Vessels (COPV) fabricated at NASA's Marshall Space Flight Center (MSFC) were available for the test program. These vessels consisted of an aluminum liner rated at approximately 500 psi overwrapped with a composite material. Once over-wrapped, the vessels had an effective ultimate pressure of approximately $2,800 \mathrm{psi}$. The COPVs were dual-ported and both ends of the vessel had a $1 \frac{11 / 4}{\mathrm{inch}} \mathrm{MS}$ port. It was determined that the flow rates, cycles times, and remaining components should be sized to function properly in the RFS configuration with these vessels as run tanks. The tank volume was 10.5 gallons, with a cycle time of a few seconds to up to 10 to 15 seconds; at the more rapid drain rates, the mass flow rates were of the order of 20 to 40 $\mathrm{lbs} / \mathrm{sec}$, which is of the order of that required for a $20,000 \mathrm{lb}$ thrust engine. For our first test series, we ran at lower outflow rates, with drain times of the order of 10 seconds. The RFS can be operated more rapidly than this, and therefore the tanks provides a margin for running a series of tests with more rapid cycle times, which we plan to do in the near future.

A triangular frame was designed for holding the three tanks and their associated valves. The triangular shape allowed us to position the tanks and lines with essentially equal lengths, which ensured that the pressure losses of the incoming and discharged liquid due to friction and bends in the pipe were approximately equal. Thus, the shape of the structure and tubing would not create small pressure and flow rate variations that could obscure the real variations we sought to determine. The frame was also designed with three cross members or shelves whose heights could be adjusted to accommodate different sized run tanks and valves for following test programs. The test article, 
shown in Figure 1, is located near the low pressure supply tank in NASA MSFC's North Test Area. This work was in part supported by a Space Act Agreement between NASA MSFC and UAH.

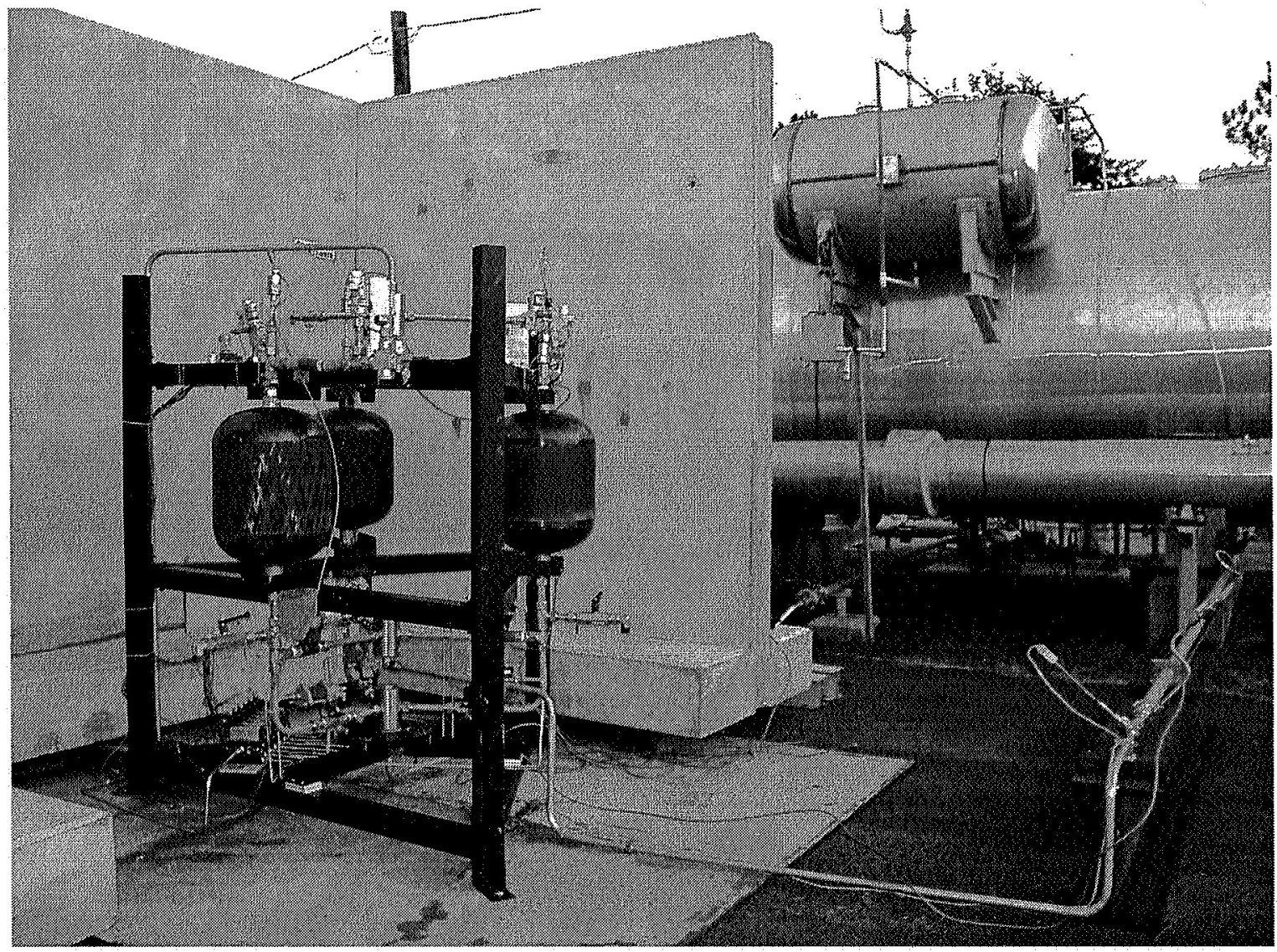

Figure 1 The discharge line and RFS test article can be seen with the main supply tank in the background 


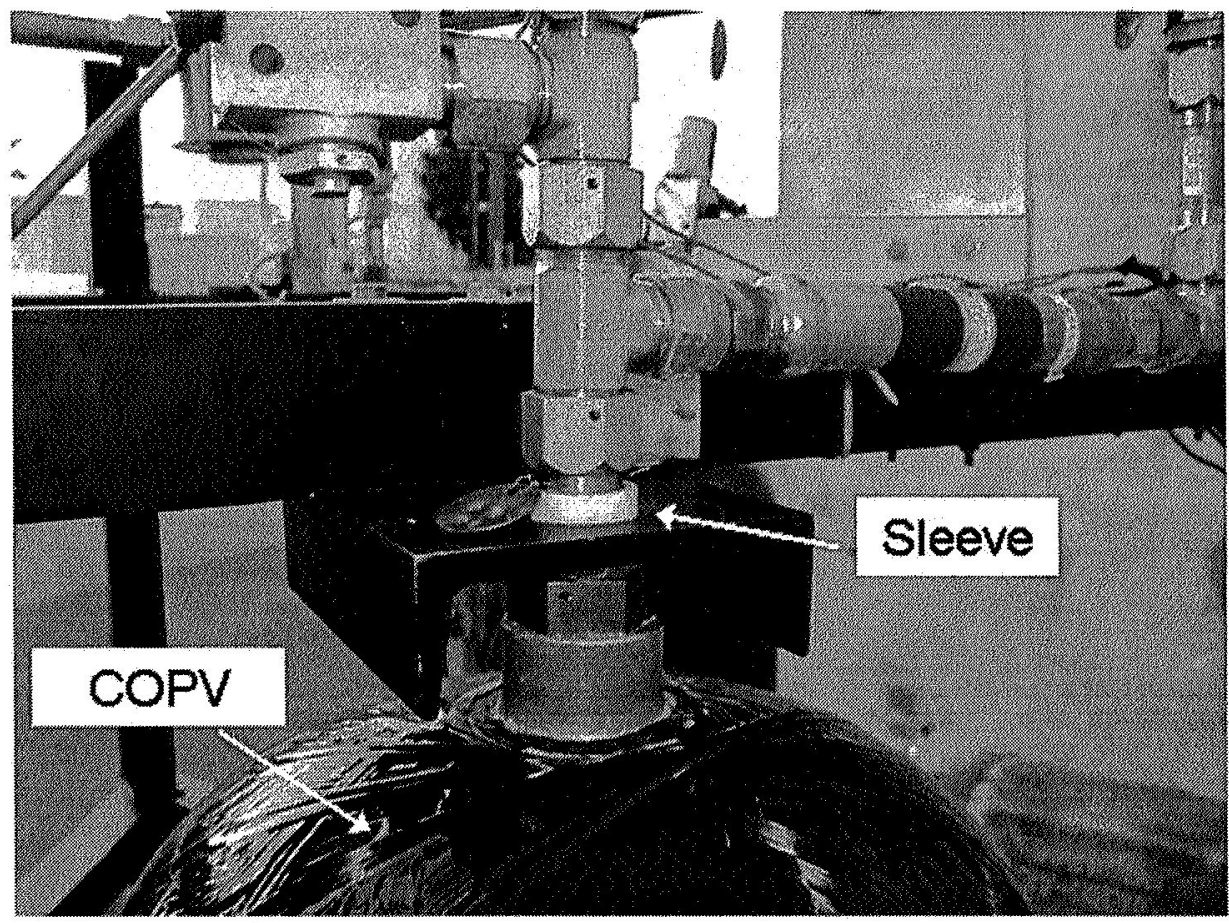

Figure 2 Setup to allow expansion of the run tanks during pressurization without stress loading the vessels

Both the top and bottom ports of each run tank were also fitted with diffusers to lower the disruption of the gas liquid interface during pressurization, to minimize liquid dropout or "chugging" during the drain process, and to minimize turbulence, sloshing, and splashing of the liquid entering during refill, and to minimize loss of liquid during the vent cycle. One-inch facility ball valves were available to function as fill and drain valves for the three tanks. These valves were equipped with pneumatic actuators controlled by small solenoid valves. One-inch facility solenoid valves were also available for pressurization and vent valves. These valves were pilot operated. In addition, we used a half-inch diameter secondary vent valve to ensure repeatable conditions in the run tanks during the fill sequence. The pressurization and vent valves were located above the run tanks and the fill and drain valves were located below. The pressurization, fill, and drain valves opened when energized and closed when de-energized or due to power loss. For safety reasons, the vent valves were set to close only when energized. This meant that in the event of a power failure, the pressurization, fill, and drain valves would fail closed and the vent valves would fail open. This was done to ensure that, in the event of an accident, no pressurization gas or water would flow to or from the apparatus and that the run tanks would vent down to atmospheric pressure, thus placing the system in a fail-safe condition. Each run tank was also equipped with a hand operated, 1 inch ball valve for manual water drainage. These valves were used for calibration procedures to determine outflow rates. The configurations of all of these valves with respect to the run tanks can be seen in Figures 3 and 4. 


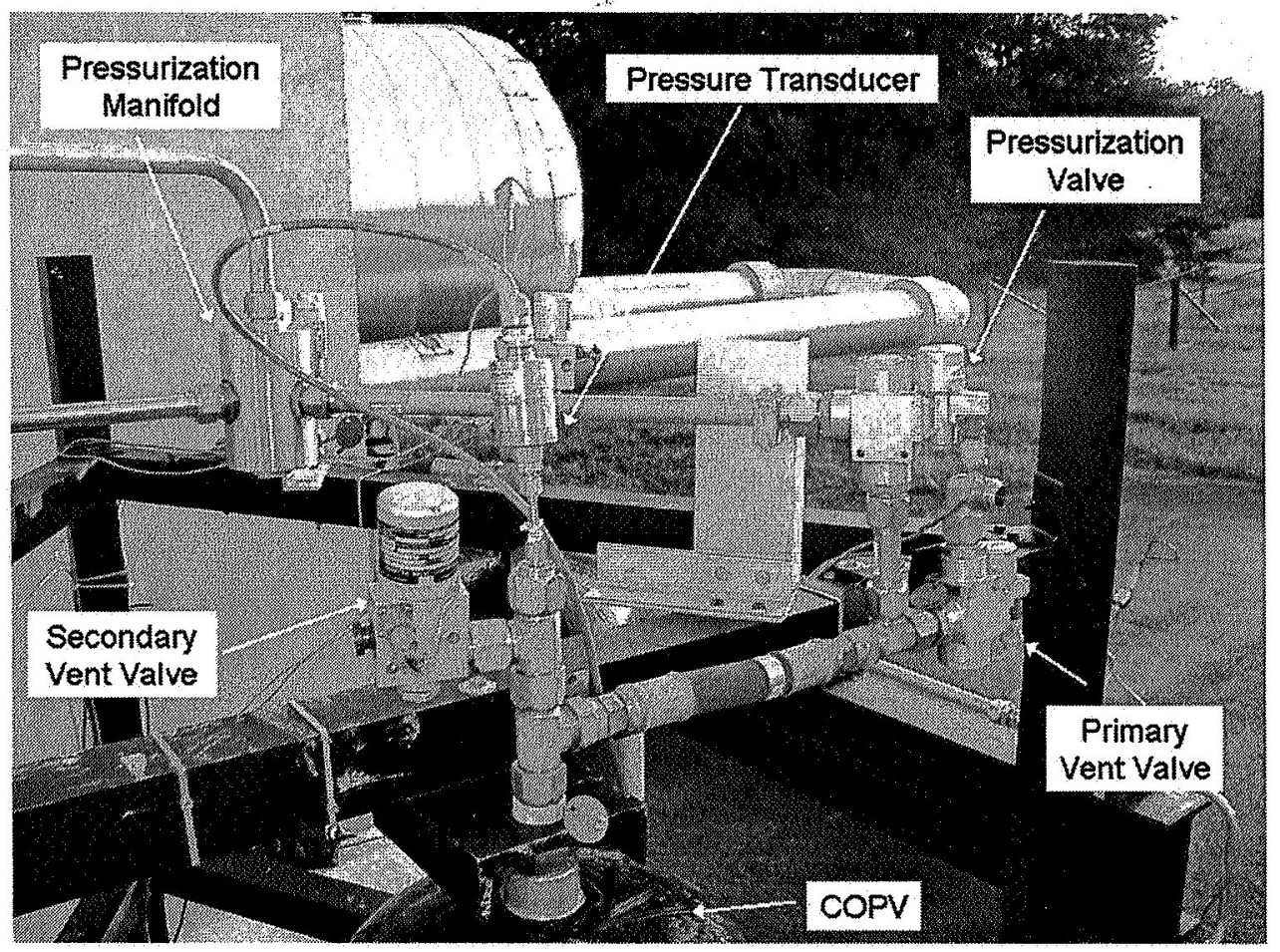

Figure 3 Configuration of vent and pressurization valves above a run tank

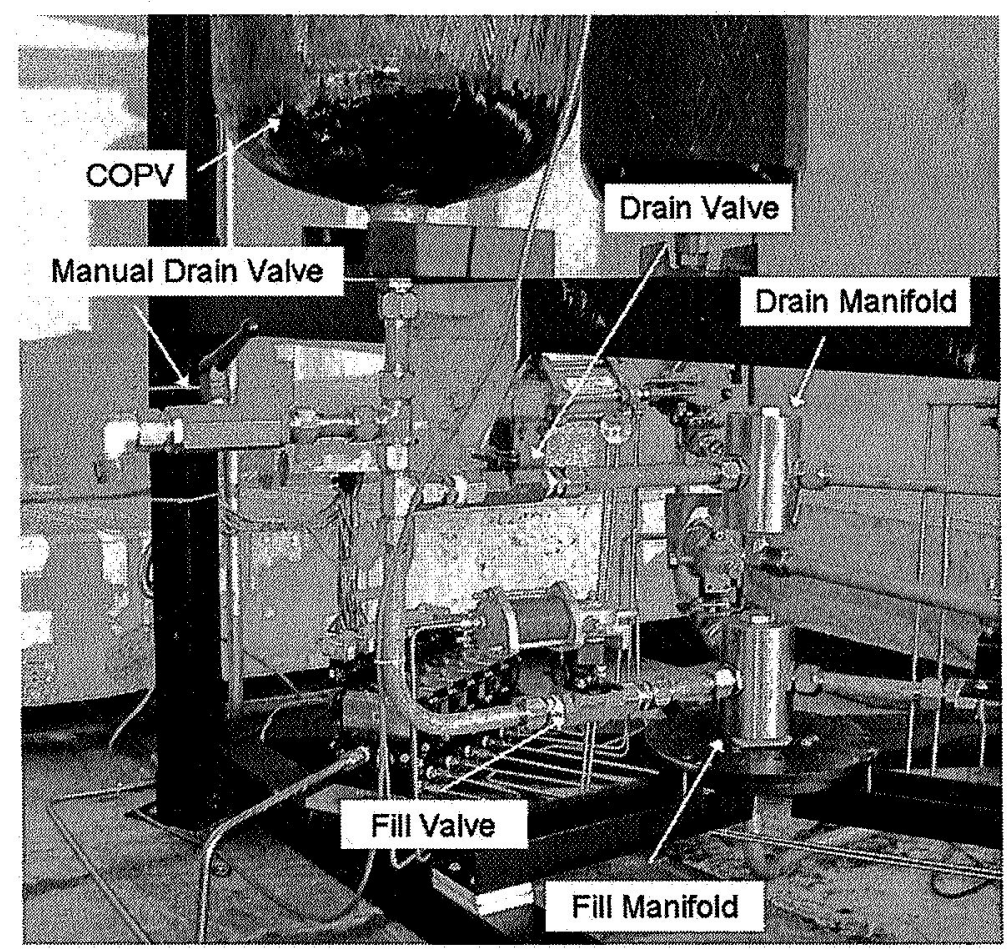

Figure 4 Typical configuration of fill and drain valves below a run tank 
Once the water was pressurized in the run tanks, it was discharged by opening the drain valves and expelling it through an orifice into a long section of 2 -inch diameter pipe. The orifice provided the necessary pressure drop to simulate flow to the engine and allowed the water to be harmlessly discharged into a nearby field. This pressure drop was also necessary to achieve the required discharge rate and relatively high pressure so that the RFS tanks would have the correct times for venting, filling, and pressurizing during the discharge cycle. In effect, the orifice and drain valve simulated the pressure conditions for an engine operating at about $500 \mathrm{psi}$. As can be in Figure 5, a pressure transducer was placed directly upstream of the orifice; this was used to estimate the flow rate by using the equation

$$
Q=C^{*} A * \sqrt{\frac{2^{*} g^{*} \Delta P}{\rho}}
$$

The large area ratio between the orifice and the two-inch discharge pipe approximately simulated discharging directly to the atmosphere and allowed for the pressure recorded directly upstream of the orifice to be considered as the $\Delta \mathrm{P}$ or pressure drop.

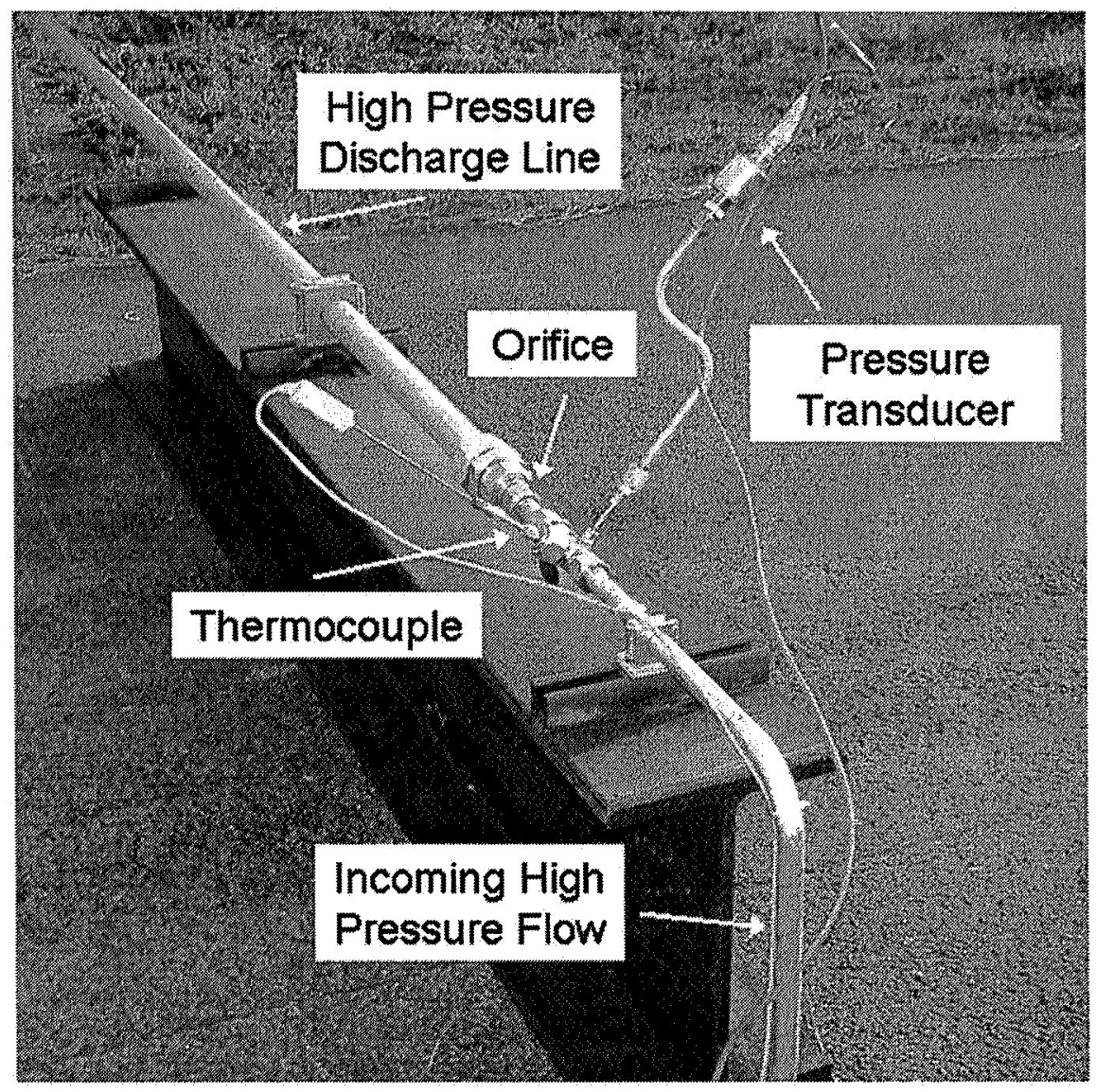

Figure 5 Configuration of transducers and orifice in the discharge line

The RFS Test Bed was located in the Marshall Space Flight Center's North Test Area. The 10,000 gallon deionized water tank was used as the low-pressure water source supplying the RFS test bed. The tank was equipped with a relief valve set at $120 \mathrm{psig}$ and could easily supply the flow rates required for filling the run tanks in seconds. A check valve was also placed in-line to prevent the high-pressure discharge of water or pressurant back into the supply tank. MSFC's North Test Area also had missile grade air supplied at 3,325 psi available the regulated pressurize for the RFS. This high purity air originated from MSFC's cross-country piping network and was filtered before entering the test area. The air pressure was reduced via a pressure-reducing panel to a first stage pressure of 
$700 \mathrm{psig}$ for pressurizing the run tanks and to two secondary stages of $150 \mathrm{psig}$ for operating the pneumatic actuators and as a spare. The main supply tank was equipped with an independent pressurization system. Since the pressure in the run tanks would be equal to the first stage pressure, the maximum stage pressure of 700 psi was chosen so that a safety factor of 4 to 1 could be maintained between the maximum allowable working pressure and the yield pressure of the run tanks. Relief valves were present in all three stages to prevent over-pressurization of the system and a check valve was placed in-line to prevent the backflow of water into the air supply line in case of an accident. A hand valve was also placed between the pressure reducing panel and test article so that the system could be isolated for leak checks, calibration procedures, or in the event of an emergency. As can be seen in Figure 1, the article was located and secured near the supply tank and blast barriers were positioned around the apparatus in case of run tank rupture. The high pressure discharge line was positioned so that it could be securely fastened to a large I-beam and the supply tank mounts. The line would discharge into an area-controlled field on the far side of the supply tank.

\section{Instrumentation and Control Systems}

The data acquisition system consisted of five pressure transducers and three thermocouples monitored by a computer program implemented in LabVIEW. Pressure transducers were used to record the pressures in each of the run tanks, the pressure of the discharge directly upstream of the orifice, and of the inflowing low-pressure water. Thermocouples were used to monitor the temperatures of the inflow low-pressure water, the discharged water just upstream of the orifice, and of the temperature of one the run tanks. Since the temperature profiles in the run tanks should approximately mirror one another during each the different processes, only one tank was fitted with a thermocouple. The data acquisition also recorded the voltages being supplied to each of the solenoid valves and thus the data files recorded the position of the valves at the times when pressures and temperatures were measured. It was determined that a sampling rate of $100 \mathrm{~Hz}$ would be sufficient to see pressure fluctuations caused by the different valves opening and closing or by alternating flow from one run tank to another. However, the system was capable of sample rates up to $1000 \mathrm{~Hz}$, and therefore every ten data measurements were averaged to produce one data point. This resulted in 100 samples per second and was done so that the data files would be manageable in Excel.

The control system consisted of 12 solenoid valves commanded by the LabVIEW program. Timing of different sequences of cycles of the solenoids was accomplished by uploading a text file into the LabVIEW Virtual Instrument (VI). The text file consisted of one column listing the times at which at least one of the solenoids changed positions and a column for each of the solenoids with zeros and ones denoting de-energized and energized states, respectively, for each of the solenoids at the listed times. The LabVIEW program continually monitored for the user to manually operate one of the solenoid valves or to begin the auto-sequence uploaded when the program began. Once the auto-sequence was initiated, the program started a timer and continually checked for the next time to change the state of any of the valves. When the proper time came for one of the valves to change position, the current was either directed to or removed from the solenoid. This process continued until all times noted by the user in the uploaded file had passed. When the auto-sequence was complete, the program began to, once again, monitor for manual operation of the solenoids by the user. The program was also equipped with an emergency stop so that the apparatus could be isolated in case of accident. The emergency stop was programmed into LabVIEW VI to place all the solenoids in the de-energized position. In the event of an emergency, this would place the fill, drain, and pressurization valves in the closed position and the vent valves in the open position. This would stop the flow of water or pressurization gas to the apparatus and would allow the run tanks to vent to atmospheric conditions.

\section{Test Matrix}

Components such as liquid level point level sensors and capacitance probe continuous level sensors were not available for this series of tests. These types of components would be vital in controlling the cycle times associated with a RFS in a vehicle. Therefore, for the initial tests the various cycle times were determined by calibration of the flow rates and times. To begin this process, the fill rate was determined. This was accomplished by filling an individual run tank for a prescribed period of time, draining the run tank, and recording the amount of water that entered the tank. This was repeated for several different prescribed times, until the inflow rate was characterized. The main supply tank pressure was held constant pressure during all of these flows. This process was repeated for each supply pressure desired for testing. Since this was time consuming, it was determined that a single supply pressure should be decided upon and used for all of these proof of concept tests.

After the fill rate was characterized, the drain and vent rates were calibrated by filling a run tank to a prescribed level, pressurizing the water to a given pressure, and then draining the tanks for a prescribed period of time. After drainage, the system was made safe and vented to atmospheric pressure. The remaining water volume 
in the run tanks was manually drained, captured, and recorded. By doing this for several prescribed times at the same pressure, the drain rate could be sufficiently characterized. The data acquisition files from these calibration runs were examined to determine the vent rate since the pressures and volumes of the pressurization gas were known.

It was not necessary to calibrate the pre-pressurization cycle. Due to the very small amount of ullage space to be pressurized in the RFS apparatus; pressurization would occur more rapidly than available solenoid valves could be controlled. Rather, the valve remained open, so that the pressure in the run tank would equalize with the pressure of the supply gas. To control this pressure, the supply would simply be set at the desired discharge pressure with a hand regulator. The pressurization valve was then closed at the end of the drain cycle.

Once calibration of the various cycles was completed, tests with pressurized outflows alternately from different run tanks were conducted. This test series allowed the pressure fluctuation resulting from switching from one run tank to another to be examined. Cycle times and hardware were adjusted to achieve different drain cycle and overlap times. This test was repeated several times, as needed, until an essentially constant pressurized outflow was achieved. Once achieved, the cycle times and overlapping valve operation times that provided the least fluctuation in pressurized outflow were used for the remaining tests.

The last sequence of test flows were to run several cycles of each of the run tanks. The first test sequence used outflows all three run tanks once. The remaining water was again collected and compared to theoretical values. In the second test sequence, outflows were conducted from all the run tanks for two cycles. Additional cycles were then tested, within the time and resources available.

\section{Experimental Results}

Our tests showed that the RFS is a viable means of pressurizing propellants for liquid propulsion systems. The following steps outline the process in which this experimentation was conducted. Calibration of each of the cycles was completed and the times required to fill, drain, vent, and pressurize the run tanks for the alternate cycling of the RFS test bed were determined. With calibration complete, test flows consisting of one complete alternating cycle of each of the tanks was completed followed by two complete alternating cycles. During these tests, pressure fluctuations were observed in the discharge flow during the transitioning of drain cycles from one tank to another. Attempts were made to lower these fluctuations by adjusting the valve sequence timing and by adding check valves downstream of the pressurization and drain valves. These modifications resulted in significantly lowering the fluctuations in pressure and outflow rate. Several other test flows were also conducted in an attempt to better understand what causes these fluctuations. The temperature profile of the run tank ullage was also recorded and the relationships of this profile to the different RFS cycles and inflow and outflow water temperatures were noted.

Once calibration procedures were complete, transitioning the drain from all three tanks was conducted. Transitioning through two complete cycles of each tank was also conducted. Since it was expected that some overlapping of the separate drains would be required for constant outflow, an overlap time of 0.5 seconds was chosen. It was thought that this time would be sufficient time to allow all the valves involved to cycle and still effectively overlap the drain cycles of each tank. The tanks were given 1 second to pressurize prior to being drained. This second, added to the 0.5 second overlap for draining means that for 1.5 seconds the pressurization valves for two run tanks would both be opened. The results from several tests consisting of a single cycle and two complete cycles were similar.

What was found in these first tests was that there was not a constant pressure discharge flowing from the system. The reason for this pressure fluctuation was that opening the pressurant valve of the next tank in the sequence exposed the first tank to an un-pressurized ullage volume. Pressurant would backflow from the discharging tank into the un-pressurized tank. This would lower the pressure in the first, discharging tank momentarily and create the large pressure drop in the discharging fluid. This pressure drop would last until the main pressurant supply could respond and provide the necessary flow rate of gas to keep both ullage spaces pressurized. The discharge pressure fluctuation was approximately $50 \mathrm{psi}$ and resulted in a water flow rate fluctuation of 0.03 gallon per second, for a normal outflow rate of the order of 0.6 gallons per second (approximately $5 \mathrm{lbs} / \mathrm{sec}$ ), or a fluctuation of $5 \%$. It should also be noted that the total fluctuation lasted for approximate 2.4 seconds.

An attempt was made to alleviate this problem by closing the pressurization valve of the first tank prior to opening the pressurization valve of the second tank. The first tank would, in effect, operate as a blow-down system for a short period of time while the drain cycles of the two tanks were overlapped. This drain overlap was again set at 0.5 seconds.

As expected the pressure profiles for both of the previous cases are similar with the total time of the pressure fluctuations being shorter in the second test. The flow rate fluctuation lasted for 1.7 seconds in the first case and 1.1 seconds in the second case. The form of the pressure profile for tank one in these tests was noteworthy. 
The pressure in one run tank begins to drop when its pressurization valve is closed. It then begins to rise again a short time later. This means pressurized flow from the second run tank must have been entering the first run tank through its drain line.

In order to correct this, a test was conducted in which there was no overlap of the drain cycles and the pressurization valves of the separate tanks were not open at the same time. By doing this, there should have been no backflow or communication between the two run tanks at all. The pressure fluctuations were of the same form as the previous tests except that there was no increase in the pressure inside run tank 1 due to backflow through the drain valve. The flow rate fluctuation was approximately $5 \%$ and lasted for approximately 0.95 seconds.

Since backflow through both the pressurization and drain valves seemed to be the cause of most pressure fluctuations, a check valve was used to ensure flow in only one direction during the next test flows. A check valve was placed between the pressurization manifold and pressurization valve of one of the run tanks. A second check valve was placed between the drain valve and the drain manifold of the same run tank. Check valves for these positions with respect to the other run tanks were not available for this series of tests. Flows were conducted in which the drain cycles were overlapped $0,0.15,0.25$, and 0.5 seconds. In each test the tanks were given 0.60 seconds to pressurize prior to draining. This means the pressurization cycles were overlapped $0.6,0.75,0.85$, and 1.10 seconds respectively. A typical transition period for a pressurization cycle overlapped by 0.5 seconds with the check valves in place is shown in Figure 6.

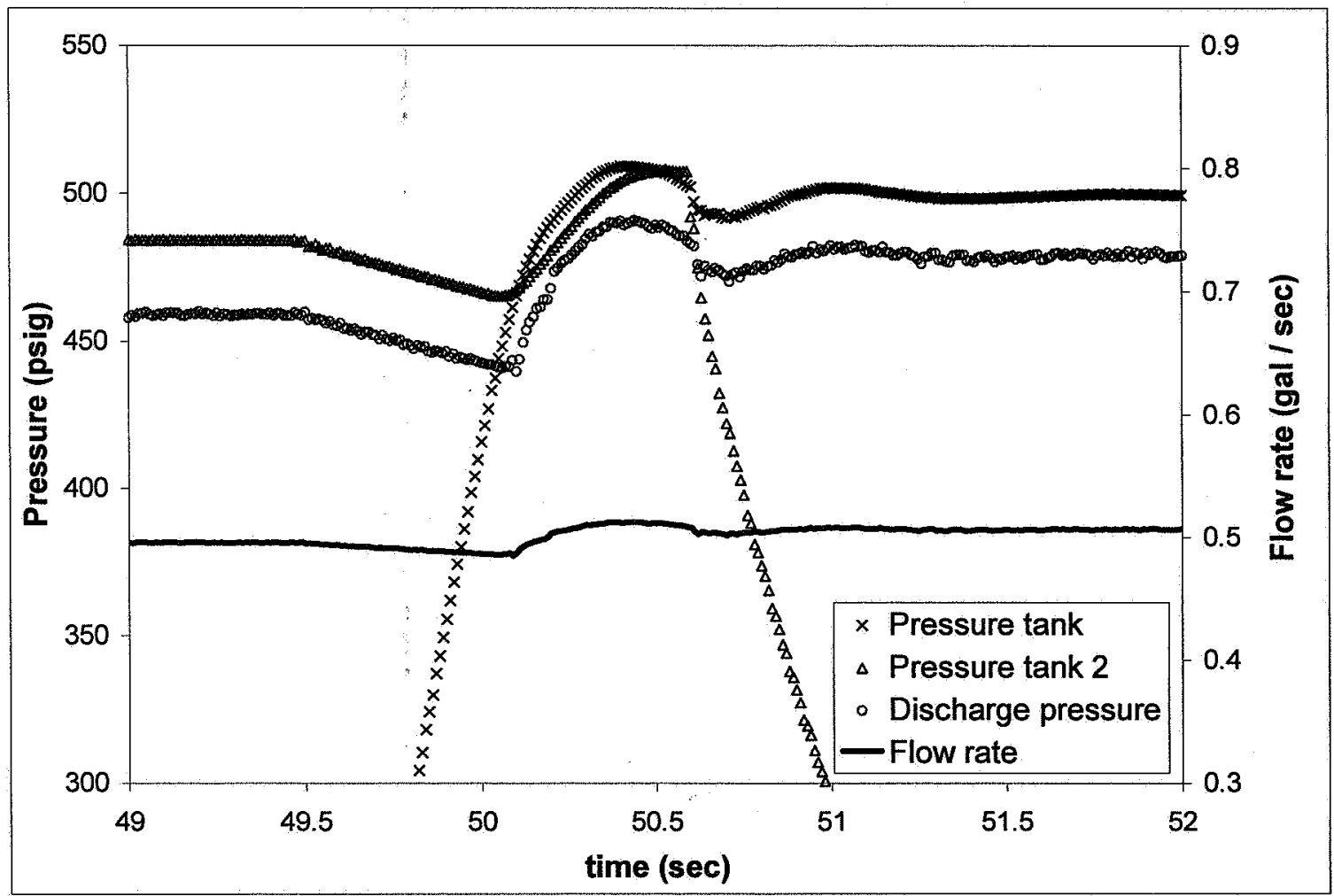

Figure 6 Drain transition after check valves were added to the pressurization and drain lines. The drain cycles were overlapped 0.50 seconds.

The overlap of the drain cycle has a significant effect on the system. As the drain overlap time increased the fluctuation in water flow rate decreased. The profile for the first tank pressurized in these figures appears to rise in conjunction with the pressure in the second tank. Since check valves were present in the drain line of the first tank, the increase in pressure must be due to the pressure increase in the supply line. This increase was due to the response of the dome loaded regulator in the pressure reducing panel. When the pressurization valve on the second tank was opened, the pressure drop that activates the regulator to increase airflow would propagate up the supply line at the speed of sound in air. The regulator could not respond instantly to fully open to allow the maximum flow rate to reach the test article, which also involved a delay. This resulted in an overcompensation that would pressurize the tank higher than the desired set pressure. The regulator would then close slightly to compensate for 
this overpressure and the ullage in the second tank would fall somewhat below the set pressure. This process continued causing the ullage pressure in the second tank to oscillate until it reached a steady state. This oscillation was reduced by overlapping the drain and pressurization cycles for longer periods of time. Typical results of these flows as well as the flows prior to installation of the check valves can be seen in Table 1. In summary, it was determined that the installation of check valves in the pressurization and discharge lines, coupled with the overlapping of the drain cycles of the run tanks, resulted in flow rate fluctuations that were brief $(\sim 1$ second) and small $(\leq 2 \%)$. Further reductions in these fluctuations could be achieved, in principle, by having small accumulators, having shorter line distances between the RFS tanks and the regulators, and using faster action regulators. However, experienced propulsion engineers considered these fluctuations, which occur relatively infrequently (of the order 1.5 seconds duration out of a cycle time of approximately 25 seconds) to not be an issue.

Table 1 Summary of the timing sequences used and the effects of those sequences on the outflow

\begin{tabular}{|c|c|c|c|c|c|c|}
\hline $\begin{array}{c}\text { Time tank } \\
\text { was } \\
\text { pressurized } \\
\text { prior to drain }\end{array}$ & $\begin{array}{c}\text { Time drain } \\
\text { cycles were } \\
\text { overlapped }\end{array}$ & $\begin{array}{c}\text { Time } \\
\text { pressurization } \\
\text { cycles were } \\
\text { overlapped }\end{array}$ & $\begin{array}{c}\text { Check } \\
\text { valves } \\
\text { installed? }\end{array}$ & $\begin{array}{c}\text { Flow rate } \\
\text { fluctuation }\end{array}$ & $\begin{array}{c}\text { Flow rate } \\
\text { fluctuation } \\
\text { duration }\end{array}$ & $\begin{array}{c}\text { Set } \\
\text { pressure }\end{array}$ \\
\hline $1.00 \mathrm{sec}$ & $0.50 \mathrm{sec}$ & $1.50 \mathrm{sec}$ & No & $5 \%$ & $2.40 \mathrm{sec}$ & $500 \mathrm{psig}$ \\
\hline $1.00 \mathrm{sec}$ & $0.50 \mathrm{sec}$ & $0 \mathrm{sec}$ & No & $7 \%$ & $1.71 \mathrm{sec}$ & $505 \mathrm{psig}$ \\
\hline $0.40 \mathrm{sec}$ & $0.50 \mathrm{sec}$ & $0 \mathrm{sec}$ & No & $5 \%$ & $1.12 \mathrm{sec}$ & $500 \mathrm{psig}$ \\
\hline $0.60 \mathrm{sec}$ & $0 \mathrm{sec}$ & $0 \mathrm{sec}$ & No & $5 \%$ & $0.95 \mathrm{sec}$ & $445 \mathrm{psig}$ \\
\hline $0.60 \mathrm{sec}$ & $0 \mathrm{sec}$ & $0.60 \mathrm{sec}$ & Yes & $5 \%$ & $1.4 \mathrm{sec}$ & $485 \mathrm{psig}$ \\
\hline $0.60 \mathrm{sec}$ & $0.15 \mathrm{sec}$ & $0.75 \mathrm{sec}$ & Yes & $3 \%$ & $1.3 \mathrm{sec}$ & $485 \mathrm{psig}$ \\
\hline $0.60 \mathrm{sec}$ & $0.25 \mathrm{sec}$ & $0.85 \mathrm{sec}$ & Yes & $2 \%$ & $1.1 \mathrm{sec}$ & $485 \mathrm{psig}$ \\
\hline $0.60 \mathrm{sec}$ & $0.50 \mathrm{sec}$ & $1.10 \mathrm{sec}$ & Yes & $1.5 \%$ & $1.2 \mathrm{sec}$ & $485 \mathrm{psig}$ \\
\hline
\end{tabular}

\section{Conclusion}

A test bed that could successfully utilize the RFS technique to simulate flow rates representative of those seen in $20,000 \mathrm{lbf}$ thrust engines was designed and constructed. This test bed was first used with water and used readily available facility hardware, such as water and missile grade air supplies, and an open loop control system. The fluctuations seen during the transition of drainage from one tank to the next was lowered from approximately $5 \%$ to $2 \%$ and durations of approximately 1.5 seconds by varying such parameters as the overlap time of the drain and pressurization cycles, the time the tanks were pressurized prior to draining, and by use of check valves on the drain and pressurization lines. These fluctuations could have been lowered even more if a faster responding main pressure regulator had been available. These fluctuations would also be lower in a flight system due to a higher fidelity, closed loop control system equipped with liquid level sensors and capacitance probes and faster acting flight type hardware. Finally, small accumulators could be used, if necessary. This test bed demonstrated the RFS technique is a feasible means for pressurizing liquid propellants and would be capable of delivering acceptably constant flow rates to a rocket engine. This proof of concept type testing and higher fidelity experimentation will continue at the University of Alabama in Huntsville Propulsion Research Center, in cooperation with NASA MSFC.

\section{Acknowledgements}

This work was supported by NASA Grant NCC8-200 with NASA MSFC with Mary Trawek as the COTR for NASA and Dr. Clark W. Hawk as Principal Investigator for the UAH Propulsion Research Center. We also wish to thank NASA MSFC personnel for their support of the RFS Test Bed development, and in particular, Mr. Kevin Pedersen, Mr. Tim Ezell, Mr. Peter Rodriguez, Ms. Becky Farr, and other members of their team.

\section{References:}

${ }^{1}$ Lanning, Mark E. and Blackmon, James B. Boeing Company, Huntington Beach, CA, Patent Application for a "Reciprocating Feed system for Fluids", Patent No.6,314,978, granted November $13^{\text {th }}, 2001$.

${ }^{2}$ Eddleman, David E., Blackmon; James B, and Moser, Marlow D., Reciprocating Feed System for In-Space Propulsion Systems. Joint Propulsion Conference, Huntsville, AL, 20-23 July 2003.

${ }^{3}$ Knight, Andrew "The Race for Low -Cost Launch Vehicles-A New Rocket Engine Design", High Power Rocketry, August 2002. 
${ }^{4}$ Harrington, Steve, "Pistonless Dual Chamber Rocket Fuel Pump: Testing and Performance," AIAA 2003-4479.

${ }^{\text {s}}$ Sobey, Alfred J. Patent Application for "Fluid Pressurizing System", Patent No. 3,213,804, granted Oct. $26^{\text {th }}, 1965$.

${ }^{6}$ Huzel, Dieter K., and Huang, David H., Modern Engineering for Design of Liquid-Propellant Rocket Engines. American Institute of Aeronautics and Astronautics, 1992.

${ }^{7}$ Cequel, Available from Software and Engineering Associates. See www.seainc.com. 